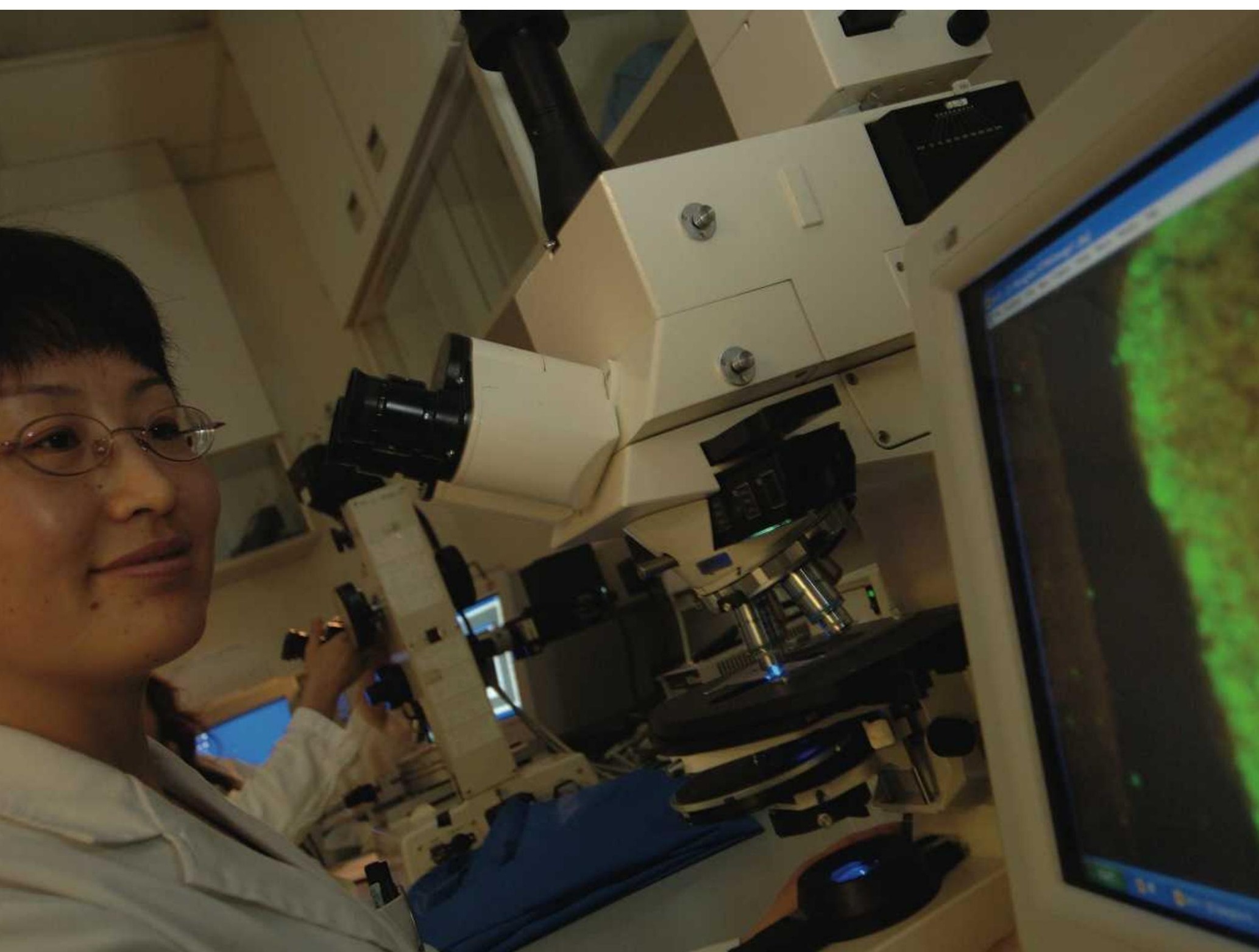

\title{
FRONTIERS
}

\section{Nano Rising}

\section{Bai Chunli}

Developing countries are investing heavily in nanoscience and nanotechnology, hoping for big payoffs.

N anoscience and nanotechnology - the study and engineering of matter at the atomic and molecular scale - have recently enjoyed rapid development in both the North and the South.

In China, the growing impact of nanoscience and technology research and development (R\&D) is on display in any number of ways. Publications have increased by 30-40\% per year over the past 5 years. According to the Scientific Citation Index (SCI), scientists from China now rank second only to scientists in the USA in the number of articles published in international peer-reviewed publications in nanoscience and technology. The number of companies in China focusing on nanotechnology now exceeds 600. That compares to less than 25 in 1990 and just over 200 in 2000.

India, the Philippines and other Asian countries have taken steps to emulate China's efforts. Governments in these and other nations, including Mexico and South Africa, have invested in nanoscience and technology R\&D, largely in fields that seek to address their nation's economic challenges. For example, India has launched a 5-year, US\$220-million national strategy for advancing nanoscience and technology. Research will focus on developing a range of materials such as carbon nanotubes, nanocrystals, nanostructured metals and inorganic substances that have applications in industrial and economic development.

As the number of exciting commercial discoveries has increased worldwide, so too has the public's interest in nanoscience and technology. Such interest provides opportunities as well as challenges.

A critical question is whether research in this field will focus on providing products or services that will serve the needs of poor people in developing counties by creating, for example, super-sensitive water filters to improve access to 
safe drinking water, or whether it will instead focus on upscale markets in developed countries to produce, for example, stain-resistant trousers. The involvement of scientists from developing countries could help to ensure that the global $R \& D$ agenda achieves a balance between the marketplace for upscale products and services and the United Nations (UN) Millennium Development Goals.

What is fuelling nanoscience and technology R\&D? In China, government priorities, public needs and rising demand for new materials prospects for public/private partnerships that combine the research skills of universities and research institutes with the entrepreneurial skills of private firms. Such partnerships will help to ease the transfer of techniques and materials that have proven successful in the laboratory for use in industry.

Advances in nanoscience and technology in the developing world have been largely dictated by the state of laboratory equipment and, more generally, the scientific infrastructure within a

\section{"Nanoscience and technology could help im- prove human health, protect the environment, and create new products and services."}

at home and abroad are among the factors contributing to advances in the field.

When it comes to building a strong foundation in nanoscience and technology, developing countries, and China and India in particular, have one distinct advantage over developed countries: they enjoy a much larger and increasingly welleducated workforce that is eager to innovate, and that demands much lower wages than their counterparts in developed countries.

In the case of China, research on ultrafine oxide particles, undertaken by the Institute of Solid State Physics and the Shanghai Institute of Ceramics in the late 1980s, spurred great interest in nanoscience and technology in China's growing scientific community. That, in turn, placed nanoscience and technology at the forefront of China's scientific and technological enterprise. Widespread use of such new techniques as scanning-probe microscopy, which allowed scientists to study single-molecule nanostructures in great depth, was another factor that helped to advance nanoscience and technology in China during the early stages of development of this new field.

For industry, researchers in China and elsewhere are exploring nanostructures to create high-performance materials. For medicine, they are turning to nanomaterials to develop new drug-delivery agents, to improve imageenhancing techniques and to develop miniaturized diagnostic devices. For the environment, they are engineering nanomaterials to extract heavy metals and organic pollutants from water and soils, setting the stage for innovative strategies for environmental remediation.

In China, India and other developing countries, such ventures are closely related to broad national strategies for improvements in environmental remediation and public health. In China, government support for nanoscience and technology currently totals about US $\$ 180$ million a year.

Developing countries such as China and India have also begun to look to the growing private sector for financial support for nanoscience and technology R\&D. This trend should help to add new sources of capital, and improve the country. In many developing countries, the state of equipment and the scientific infrastructure have not been good.

That is why the research agenda in the developing world has largely taken its cues from research initially done in the developed world. At the same time, scientists in the developing world have not had access to a large and dynamic private sector to help transform discoveries into applications. This is especially true for microfabrications and nanodevices.

The next step for developing countries in their efforts to compete on a global scale in nanoscience and technology is to focus on efforts to promote technology transfer. That requires attention to be placed on management, marketing and gaining access to venture capital.

Developing countries, particularly large countries like China and India, have built a strong scientific foundation in nanoscience and technology. It is now time to emphasize innovation and commercialization so that nanoscience and technology can be put to use for the benefit of people and the economy.

Nanoscience and technology could play a central role in improving human health, protecting the environment, and creating new products and services that improve lives in ways both big and small. Universities and research institutes could contribute a great deal to such efforts by presenting unbiased assessments of the potential benefits of nanoproducts and services, and by evaluating the potential hazards that they might pose for the environment and human health.

Building broad public confidence in the safety and value of nanoscience and technology is fundamental to success. Nanoscience and technology are among the few fields where cutting-edge research can translate into immediate benefits to society. That is good news for science and societies everywhere. It provides just one of many reasons why the world needs the full and active participation of scientists in developing countries.

Bai Chunli (TWAS Fellow 1997) is executive vice president of the Chinese Academy of Sciences in Beijing, China.

\section{VIEWPOINT I Ana María Cetto Why poor countries need nuclear research capacity}

For many readers, the phrase 'nuclear research' is often taken in the context of defence or national security. What is less known is that in developing countries, applications of nuclear research have had far-reaching impacts on, for example, public health, food security and the management of natural resources. In Africa, a growing number of nations are using nuclear techniques to identify drug-resistant strains of malaria, tuberculosis and HIV, to detect the active transmission of tuberculosis and to explore the development of vaccines against HIV. Nuclear research in Central America has led to the development of low-cost feeding strategies for livestock to enhance milk and meat production through better nutrient uptake. In Asia, mutation-breeding techniques have been used to develop drought-resistant sorghum and saline-resistant rice. Initiatives to enhance yields for barley, cassava, millet, yams and many other crops are having a positive impact on the lives of people in poor countries. Isotope-hydrology applications, moreover, are allowing governments to manage their water resources better. In some cases, this has resulted in transboundary cooperation - for example, to support the sustainable development of the upper Lempa River water basin, which is shared by Guatemala, Honduras and El Salvador. Isotope hydrology has also been essential to investigate and manage groundwater and geothermal resources in Ethiopia, and to identify safe drinking water in Bangladesh, where arsenic contamination of water has caused a major health crisis. Some 120 developing countries - nearly every developing country that is a member of the International Atomic Energy Agency (IAEA) - have developed some capacity in nuclear research and applications for public health and the environment.

Ana María Cetto (TWAS Fellow 1999) is the head of the Department of Technical Cooperation at the International Atomic Energy Agency (IAEA) in Vienna, Austria. 